\title{
Exploration on the Transformation of Teaching Pathways in Craft Skills of Dongguan Intangible Cultural Heritage in the Era of Big Data
}

\author{
Su Zhuan \\ Department Of Art and Design, Guangdong University of Science \& Technology \\ Guangdong, China
}

\begin{abstract}
The development of the digitization of image resources is moving rapidly in the era of Big Data, especially in the preservation of art and craft works of the Dongguan Intangible Cultural Heritage. Through understanding the image semantic resources in Dongguan Cultural Heritage, a new teaching pathway could be created by integrating traditional images into an art design course in college. This will enrich the teaching content dynamically and inspire the creativity of students. The innovation will also play an active role by effectively inheriting and protecting the traditional culture.
\end{abstract}

Keywords-dongguan intangible cultural heritage craft skills; image resources; transformation of teaching pathway

\section{THEORY OF ICONOLOGY}

Iconology has become an important branch in the fields of art and design and art history. This study covers not only the evolution of emblazonry, ornamentation, and patterns, but also reflects the inner meanings of general and cultural history, psychology, philosophy, and semiology, even relating to religious studies. Thus, the research of emblazonry, ornamentation, and patterns is by no means a simple study of decorative art.

Decorative images could be symbolic symbols, which has become a recognized fact in the academic world. In his book The sense of order - Study in the Psychology of Decorative Art,E.H.Gombrich, the art historian, on the topic "As a Symbol of Design", points out both the importance of studying the etymology and the symbolic meanings of the pattern. Recognizing the symbolic meaning behind the pattern will lead to understanding of the cultural vision in a certain period. In addition, the formalism representative, Alois Riegl, mainly elaborated on the "diachronic" unified view of style development in his book, Problems of Style: Foundations for a History of Ornament (1992).

Erwin Panofsky, a German-Jewish art historian, was the most eminent representative of modern academic study of iconology. In his book Studies in Iconology, he stated that the analysis of images should have three levels: First, "Primary or Natural Subject Matter": this stratum consists of perception of the work's original form, devoid of any added cultural

The paper is funded by the Guangdong Higher Education Teaching Reform Project, Guangdong [2018] No. 180. Project Name: “ Integration of crafts skills on Qian-Jiao Lantern of Dongguan Intangible Cultural Heritage with Visual Communication Design Teaching Practice Research". knowledge. Second, "Secondary or Conventional Subject Matter (Iconography)." This stratum goes a step further and brings to the equation of cultural and iconographic knowledge. Third, "Tertiary or Intrinsic Meaning or Content (iconology) Matter." This level takes into account personal, technical, and cultural history into the understanding of a work. It looks at art not as an isolated incident, but as the product of a historical environment. Erwin Panofsky's image analysis uses content analysis as a starting point to explain the symbolic meaning of art works based on the background knowledge of traditional history.

Through the above analysis of iconology, it is intended to analyse the art and craft works in Dongguan Intangible Cultural Heritage by the relevant theory of imageology, and explore the cultural value hidden behind it.

\section{IMAGE ANALYSIS OF FOLK ART AND CRAFT FROM DONGGUAN INTANGIBLE CULTURAL HERITAGE}

Dongguan is one of the ancient towns in the Pearl River Delta which belonged to NanYue County during the Pre-Qin period (221 B.C.). It is one of the important birthplaces of the LingNan Civilization and has rich intangible and tangible cultural heritage. According to the 2003 Convention for the Safeguarding of the Intangible Cultural Heritage by UNESCO, the Intangible Cultural Heritage ( $\mathrm{ICH})$ refers to the practices, representations, expressions, knowledge, skills - as well as the instruments, objects, artefacts and cultural spaces associated therewith - that communities, groups and, in some cases, individuals recognize as part of their cultural heritage. Therefore, it is of great significance to correctly understand and grasp the connotation of Dongguan $\mathrm{ICH}$ to enable effective protections. That would also play an extremely important and positive role in promoting social harmony and boosting the cultural confidence in the community. As the carrier of Dongguan culture, ICH shows the diversity of local culture, connecting Dongguan historical traditions, contemporary life and future cultural development.

Under the influence of multiculturalism, ancient cultural forms have been heavily impacted; some gradually lose their original appearance, becoming assimilated or even alienated. For example, the treasure in the ICH Exhibition Hall of 
Dongguan, Qian-Jiao Deng, (literal meaning: Thousand-Angle Lantern) as a carrier of local culture and art, had been rated as a national-level ICH in 2006. It was first created during the Song Dynasty with exquisite craftsmanship, well known as the "Eternal Lights", and is presented with lots of symbolic features. The gigantic art piece measures 4.5 meters in height and 3.5 meters in width which took at least one year to finish. It is amazing that this traditional art piece has been recreated by craftsmen through oral communication and hands-on tutoring for over a thousand years with no written instructions. However, it is now deeply concerning that only one craftsman who was trained by his father is able to make the lantern, so it is a challenge for us to ensure that the craft skills are transmitted from generation to generation.

3 items from 36 pieces of folk art and crafts from Dongguan ICH selected for the features to be analysed (see the following table):

TABLE I

ITEMS DONGGUAN INTANGIBLE CUltural HeRITAGE

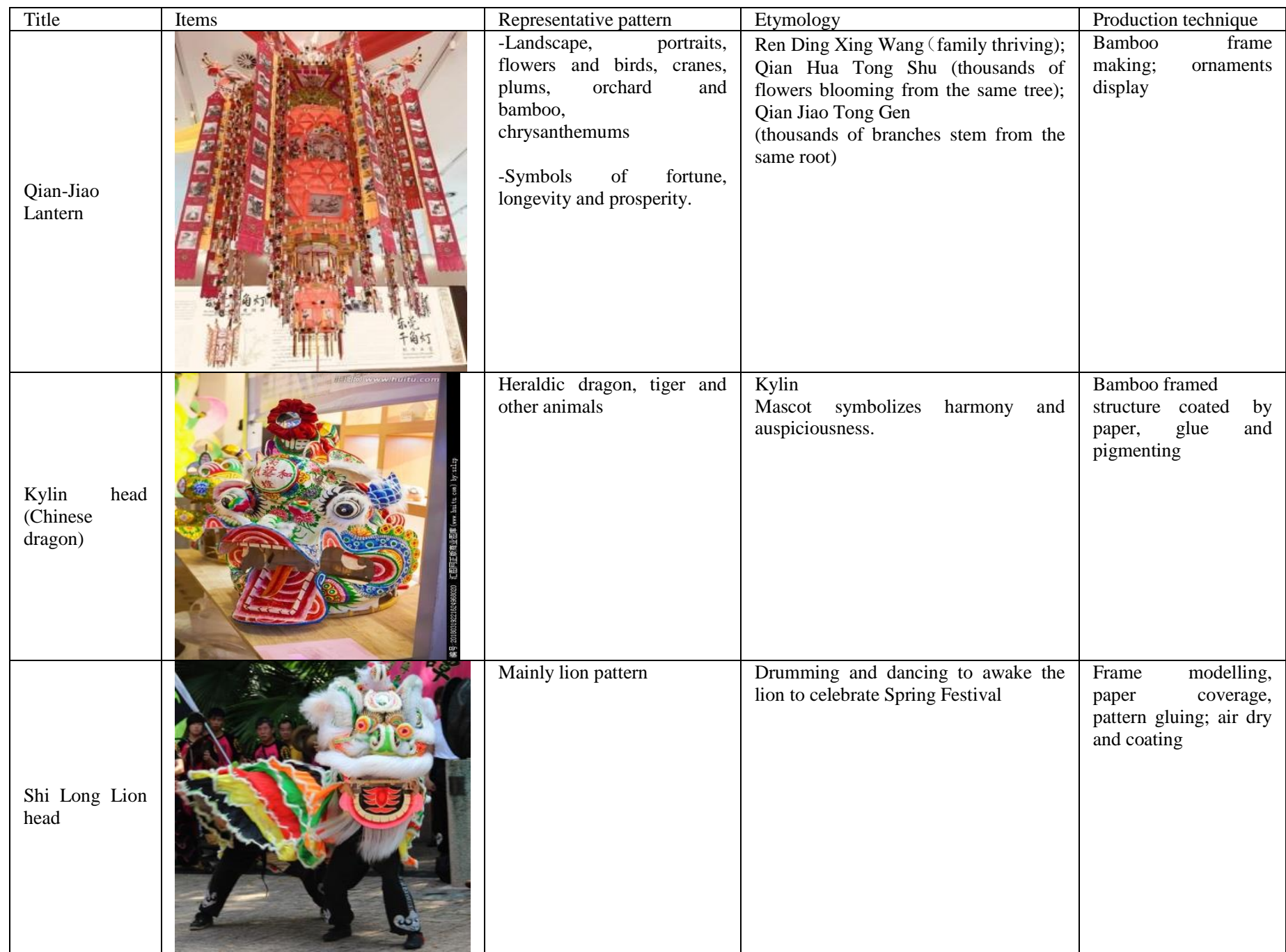

According to the above summary of craftsmanship in Dongguan ICH, the following image analysis could be carried out in three aspects. The first aspect would be the "original image description." In the case of the Qian-Jiao Lantern, it is a gigantic palace lantern that consists of a top, body, pillars, streamers and a tail handcrafted by different patterns, color, and shapes. The top is octagonal, with each corner attached to a three-dimensional flying dragon. Each corner also has three long, willow-like streamers from top to bottom, each of which is decorated with a handcrafted pattern of landscapes, figures, flowers and birds. The body of the lantern is presented with both abstract geometric shapes and natural scenery. The second aspect, "the conventional form analysis," is often backed up by a legend or an identifiable character. For example, the Qian-Jiao Lantern is used by ancestors of Zhao's family to welcome a new-born boy into the clan, while the Shi-Long Lion is used to celebrate the Spring Festival. In the third aspect, "the symbolic image analysis", the images of cranes on the Qian-Jiao Lantern stand for celebration of birthdays and longevity. On the other hand, the dancing lions symbolise scaring away evil and facing the challenges of a new year.

The image symbols from folk art and crafts in Dongguan ICH have been used to express a desired reality of human beings for eternity of time and space. It also reflects the philosophy of "Tian Ren He Yi"( Human beings and natural 
world are in one) in traditional Chinese culture. By observing nature and reflecting, Dongguan people have developed their unique psychological insights and have presented them in different forms of visual arts.

\section{EXPLORING A NEW TEACHING PATHWAY BY USING IMAGE RESOURCES FROM FOLK ART AND CRAFTS IN DONGGUAN ICH FOR ART AND DESIGN COURSE}

The American scholar Carla J. points out that "the identity of the nation refers to the individual's belief in the nation, its attitude, and the recognition of its own national culture." The renowned architect I.M. Pei said, "the more national, the more global." Therefore, it is worthwhile to integrate the image resources of Dongguan ICH into college education. Nurturing the young adults with rich original images resources in $\mathrm{ICH}$ would help them develop their sense of cultural identity and draw the essence from our traditional culture, and eventually ensuring that the local ICH would be inherited creatively.

\section{A. Extract teaching content from original images of Dongguan ICH}

Combing classic images from folk art and crafts in Dongguan ICH with modern aesthetics would be an unique

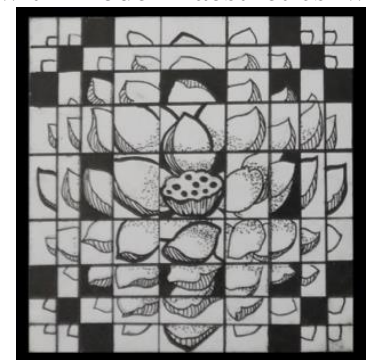

Fig. 1: Lotus Pattern Design

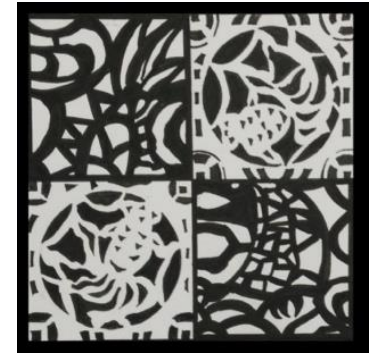

Fig. 2: Goldfish Pattern Design

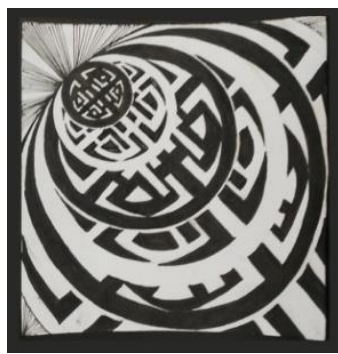

Fig. 3: "Shou" Pattern Design
B. Understanding the high cultural context in traditional images of Dongguan ICH, images could be reproduced with a modern reappearance by a new way of digital design

The concept of design and perspective of aesthetics are constantly changing as there has been an exponential increase of information in the Era of Big Data. Dongguan ICH has been germinated and evolved in local social and cultural contexts throughout history. It stands the test of time while shares and bears the memory and the emotional attachments of the locals. The Qian-Jiao Lantern, pronounced as "Qian Ge Ding" in Dongguan dialect, interpreted as "population or baby booming", has carried their wishes of peace and prosperity forever.

By encouraging young adults to grasp the essence of $\mathrm{ICH}$ and appreciate the everlasting glamour of the classic images, way of teaching art and design courses. With the help of technology such as smartphones and digital cameras, images and stories could be collected and recorded anytime and anywhere for inspiration. Take the Qian-Jiao Lantern for example, creative design could be analysed as follows:

Fig.1, The original image of a Lotus, a symbol of pureness, has been rearranged into petals by structural graduation. The new design has a strong sense of order and space.

Fig.2, The Goldfish, a symbol of affluence and reproduction, recomposed in repetition plus the positive and negative heraldic change. A prosperous visual effect has been vividly displayed from the original papercut.

Fig.3, The Chinese character "Shou", one of the traditional ornaments, symbolises longevity along with endless fortune. In this work, the character "Shou" had been shaped from small to large gradually plus the negative and positive changes, leading to a brilliant final design full of patterns, rhythm and a sense of order and space. the traditional elements have been dynamically recreated with brand-new shapes and modern materials. A local contemporary cultural icon could emerge from these works in the nearest future. Three pieces of artwork from students are presented as follows:

Fig. 4, The 3D hollowed folded book was designed and made by using traditional techniques of paper cutting and hollowing.

Fig. 5, 6, Lighting products were reproduced with bamboo strips and Chinese Xuan paper, the same materials as the Qian-Jiao Lantern. Modified patterns of the butterfly and the "Fu" character (meaning "blessings" in Chinese), are hollowed out from Xuan paper, while the lighting brings out the visual effect of vogue. 


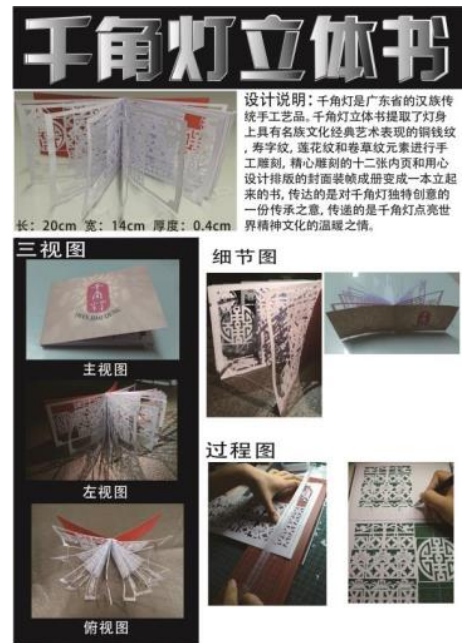

Fig. 4, 3D book design

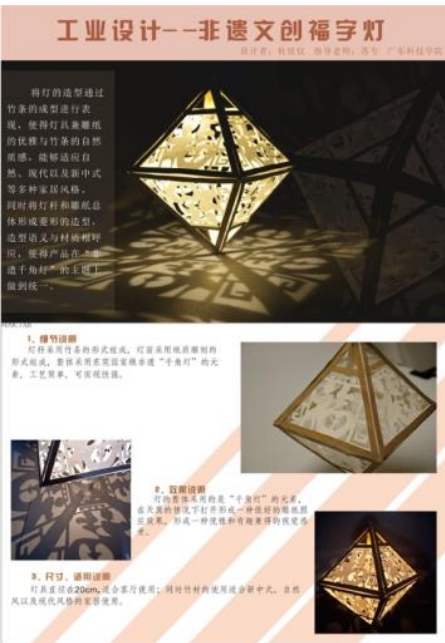

Fig.5, "Fu” lamp design


Fig. 6, Butterfly lamp design

\section{CONCLUSION}

In summary, the transformation of teaching pathways from images resources in Dongguan ICH is an exploration on integration of traditional elements and digital design. It could be implemented through combining images in Dongguan ICH with $2 \mathrm{D}$ and $3 \mathrm{D}$ compositions to create new fine arts filled with a unique Chinese style. Those final products embedded with modern aesthetics will inspire the students' creativity and nurture their sense of cultural belongings. Furthermore, it could help the Dongguan ICH to sustain and to regenerate.
[1] E.H. Gombrich The sense of order - Study in the Psychology of Decorative Art, Oxford: Phaidon 1979

[2] Alois Riegl, Problems of Style: Foundations for a History of Ornament (Princeton, 1992)

[3] Panofsky, Erwin (1972-01-01) Studies In Iconology: Humanistic Themes In The Art Of The Renaissance Studies in Iconology Harp\& Row

[4] McCowan, Carla J. \& Alston, R. J. (1998). Racial identity, African self-consciousness, and career decision making in African American college women. Journal of Multicultural Counseling and Development, 26(1), 28-38 